\title{
An update of impact of obesity on female infertility and its management
}

\begin{abstract}
With the increase in worldwide incidence of obesity the incidence of obese infertile couples has significantly increased. Obesity has a significant effect on the outcomes of in vitro fertilization with clinical impact on oocytes, endometrium as well as preimplantation embryos. Also it takes longer time for stimulation with higher doses of gonadotropins, greater time for stimulation along with higher cancellation cycles raising the cost factor. Further obesity is associated with higher incidence of PCOS along with its metabolic sequelae. Pregnancy in obesity is further confounded with multiple complications like $\mathrm{PIH}$, higher incidence of preterm labour, still birth incidence along with greater chances of caesarean delivery. Yet there is no certainty whether prior weight reduction therapies help in achieving better incidence of live birth rates with poor efficacy of currently available antiobesity therapies and even the most effective bariatric surgery. More studies are needed to develop better antiobesity drugs and study bariatric surgery with prospective trials for improving the understanding of effectiveness of obesity treatment prior to pregnancy.
\end{abstract}

Keywords: female infertility, obesity, HPO
Volume 4 Issue 2 - 2018

\author{
Kulvinder Kochar Kaur,' Gautam Allahbadia, ${ }^{2}$ \\ Mandeep Singh ${ }^{3}$ \\ 'Scientific Director, Kulvinder Kaur Centre For Human \\ Reproduction, India \\ ${ }^{2}$ Scientific Director, Rotunda-A Centre for Human reproduction, \\ India \\ ${ }^{3}$ Consultant Neurologist, Swami Satyanand Hospital, India
}

Correspondence: Kulvinder Kochar Kaur, Scientific Director Kulvinder Kaur Centre For Human Reproduction, 72I, G.TB Nagar, Jalandhar- I4400 I, Punjab, India,Tel 9 | I8I 950।358|80, Fax9|-|8|-46|3422,Email kulvinder.dr@gmail.com

Received: June 14, 2017 | Published: March 12, 2018

\section{Introduction}

Obesity is increasing worldwide having reached epidemic proportions globally with the increasing incidence one encounters more obese women in infertile clinics worldwide. ${ }^{1-3}$ We have reviewed the aetiopathogenesis in our early reviews and how it impacts management .Here we further emphasize and update its effects on infertility treatment and further on management. ${ }^{4-7}$

Obesity has a negative effect on reproductive potential due to functional changes in the Hypothalamo-Pituitary-Ovarian (HPO) axis. Obesity is often associated with hyperinsulinemia,a known stimulus for increased androgen production. ${ }^{8}$ Androgens get converted to oestrogen $(\mathrm{Og})$ in periphery namely in Adipose tissue (AT) present in excess $=>$ negative feedback on the HPO axis and thus affecting gonadotropin production. ${ }^{9}$ This presents with menstrual abnormalities along with ovulatory dysfunction. Hyperinsulinemia is commonly found to be an aetiopathological factor of PCOS .Obesity contributes to insulin resistance(IR) and exacerbates the symptoms of PCOS with obese women often showing a more severe phenotype. ${ }^{10,11}$ Increased androgen levels in $\mathrm{PCOS}=>$ further accumulation of visceral fat accelerating IR and hyperinsulinemia and thus stimulating more ovarian as well as adrenal androgen production in a perceptual cycle. ${ }^{12}$ Prevalence of PCOS in some obese populations approaches $30 \%$ although causative role of obesity in PCOS development has not been established. ${ }^{13-15}$ Various studies have shown that obese women take a longer time to conceive. In a Danish cohort of women planning pregnancies showed decrease in fecundity ratios with increasing BMI's. ${ }^{16,17}$ Obese women do not conceive despite not having ovulatory dysfunction. On examining a large American cohort of $>7000$ ladies, Law et al showed reduced fecundity in eumenorrheic obese women[18].Further data given from a huge Danish cohort by van den Steer in 3000 ladies with normal cycles, probability of spontaneous conception reduced linearly with each BMI point $>29 \mathrm{~kg} /$ $\mathrm{m}^{2} .{ }^{19}$ Obesity also affects ART results providing a direct scenario that the pathologies lie beyond the ovulatory disorder .Obese women who undergo IVF have smaller oocytes which are less likely to fertilize normally. ${ }^{20,21}$ Various studies have shown a negative impact on live birth rates(LBR's)and this appears to correlate with increasing BMI. ${ }^{21-24}$ In a review of ART in both overweight and obese women showed a modest impact on LBRs with a pooled odds ratio of 0.90 but in a large study of women with class III obesity $(\mathrm{BMI}>40 \mathrm{KG} / \mathrm{m} 2)$ there was a $50 \%$ reduced probability of live birth..$^{21,25}$

\section{Effect on HPO axis}

Animal models along with human studies show that obesity has an impact on the HPO axis. In mice model with DIO it was shown by Tortorellello et al. ${ }^{26}$ that there was a $60 \%$ reduction in natural pregnancy rates but that the defect could be overcome with the use of exogenous gonadotropins implicating a central mechanism. ${ }^{26}$ The same group also engineered a mouse model with genetic mutations $=>$ an obese and infertile phenotype independently from the diet. They found mice who were resistant to developing the phenotype had >levels of leptin receptors in the hypothalamus. ${ }^{27}$ Obese women have greater levels of leptin, a cell signaling protein as compared to normal matched controls which might $=>$ down regulation of its receptor in the brain .It is seen that women who have>leptin concentrations and increased leptin-BMI ratios have lower rates of pregnancy with IVF. ${ }^{28}$ Jain et al. ${ }^{29}$ studied eumenorrheic obese wonen and found that amplitude of LH pulsatility was significantly reduced which also supports that there is a significant central defect in obesity. ${ }^{29}$

\section{Oocytes and obesity}

Women who are obese and undergoing IVF have altered follicular environment with $>$ insulin, triglyceride levels along with inflammation markers like lactate and CRP in follicular fluid(FF). ${ }^{30}$ Also there is $>$ need of gonadotropin doses and longer treatment courses required for follicular development. ${ }^{31,32}$ Oocyte yield also is lower in obese women with >number of cycle cancellations. ${ }^{32,33}$ In DIO mouse models the ovaries show higher apoptotic follicles and oocytes smaller and < likely to mature. ${ }^{34}$ Higher rates of meiotic aneuploidy and fragmented disorganized meiotic spindles and chromosomes which are not aligned on the metaphase plate. ${ }^{35}$ Similarly Machlinger et al. ${ }^{36}$ examined oocytes which failed to fertilize in IVF cycles of morbidly obese 
women. They Similarly showed disarrayed spindles with misaligned metaphase chromosomes. ${ }^{36}$ Besides aneuploidy obesity also alters mitochondrial function in oocytes. It has been seen that mitochondrion in DIO mice have disrupted architecture with fewer cristae, more vacuoles and evidence of swelling. ${ }^{35}$ There is also a change in distribution of mitochondrion with clumping throughout the ooplasm compared with uniform perinuclear localization in control subjects. ${ }^{37}$ There is evidence of metabolic stress in these mitochondria with lower levels of citrate, which is a tricarboxylic acid cycle end product. Due to this stress there may be a compensatory higher mitochondrial production as evidenced by higher mitochondrial DNA copy number in oocytes of obese mice..$^{35,37,38}$ Also there is higher Endoplasmic reticulum (ER) stress in obese state (as reviewed in ref 4). Cumulus oocyte complex of mice fed a high fat diet show increased expression of ATF4 and GPR78 and increased granulosa cell apoptosis. ${ }^{39}$ This has a correlation with increasing activating transcription factor levels in follicular fluid of obese women undergoing IVF. ${ }^{39}$ Similarly impaired oocyte competence is seen in obese PCOS women which is associated with lower pregnancy rates along with ovulation induction and altered FF biomarkers but these studies have to be taken with a pinch of salt as there are lot of metabolic disturbances along with obesity in women with PCOS. ${ }^{40}$

One reason for oocyte organelle damage in obesity is lipotoxicity. Excess FA's obtained from the diet get stored as triglycerdes in adipocytes and they do not appear to cause cellular damage in this storage compartment. Once storage capacity is overachieved secondary to over eating FA's accumulate in other tissues like muscle ,liver and heart causing lipotoxicity. ${ }^{41}$ Higher circulating FA's cause damage to non adipose cells due to increase in ROS which causes mitochondrial and ER stress=>apoptosis. ${ }^{42}$ Those having IVF, have increased FFA in FF correlates with abnormal morphology of cumulus-oocyte complex. ${ }^{43}$ Oocytes in obese mice have two fold increased production of ROS along with depleted glutathione which is an important cellular defense against ROS damage. ${ }^{37}$ Lipotoxicity plays a role in development of IR and an increased inflammatory state in obese women. ${ }^{44}$

Also obesity is a state of chronic low grade inflammation (reviewed in ref 4]. Inflammatory pathways are important in reproductive pathways like follicular rupture during ovulation and also for invasion of trophoblast into receptive sites. Developing blastocyst produces adiponectin, IL1 \& IL6. ${ }^{45}$ Hence altered inflammatory milieu in obese women exerts an influence on these processes.

Also greater leptin is also correlated with increased leptin in follicular fluid.46In vitro studies showed that leptin affects steroid production in a dose dependent manner. ${ }^{47-50}$ Effects of obesity at level of oocyte may have downstream effects on endometrial receptivity and embryo implantation.

\section{Embryos and obesity}

Human IVF cycle with autologous oocytes show that obese women have greater chance of making poor quality embryos. ${ }^{51,52}$ Dams having DIO where mouse embryos are created have lower expression of IGF1R,which negatively affects insulin sensitivity and glucose transport at a critical stage in development. ${ }^{34}$ Embryos in women with $\mathrm{BMI}>25 \mathrm{KG} / \mathrm{m}^{2}$ were less likely to develop after fertilization as found by Leary et al. ${ }^{53}$ and that ,those that actually reach morula stage developed more quickly. Also the ones which developed to blastocyst stage had lesser cells in the trophectoderm and showed poor glucose uptake and increased levels of triglycerides. ${ }^{53}$ Similar to oocytes embryos were also more susceptible to lipotoxicity. Murine embryos were cultured in the media having high palmitic acid had lower nuclei and altered IGF1R expression. On trying to transfer these embryos in dams, pups born had lower birth weights but normal catch up growth just like in DIO models. ${ }^{54}$ Also murine trophoblastic stem cells which were exposed to palmitic acid in vitro proliferated less and undergo increased apoptosis in a dose dependent fashion. ${ }^{54}$ Raised levels of omega 3 fatty acids like $\alpha$ linoleic acid in women who were having IVF done had lower pregnancy rates..$^{55}$ Greater ratio of linoleic acid and omega 6 fatty acid:alinoleic acid showed higher pregnancy rates in that population. ${ }^{56}$

Besides acting centrally raised leptin has a direct negative impact on the developing embryo. Leptin has a stimulating effect on human trophoblastic stem cells growth, and its inhibition reduces proliferation and dramatically increases apoptosis..$^{57}$ Raised levels of leptin in obesity may decrease the sensitivity of the trophoblast to its effect.

\section{Obesity and endometrium}

Despite investigators showing no effect on implantationrates, ${ }^{58,59}$ in a retrospective review by Desolle et al.$^{60}$ of a 450 donor oocyte frozen embryo transfer cycles there was an impact of BMI on success. ${ }^{60}$

Both mice studies as wll as human studies show endometrial decidualization is impaired in obesity. ${ }^{46,61}$ In the same study the authors looked for decidualization in primary cells from obesity vs control women and found a decrease in obese women. Both the mice and human studies showed a relationship between decidualization and the process of autophagy, a self eating, which is triggered by starvation. Many factors contribute to poor reproductive outcomes and the studies by Broughton et al suggested that the importance of decidualization defects. These defects may add to compromised endometrial receptivity and poor implantation. Placentation process might get affected by these defects and associated with pregnancy complication like still birth, PIH. Role of obesity and first trimester abortions is again debatable. In an Italian study 700 women undergoing donor oocytes cycles found significantly $>$ spontaneous abortions in obese women 38.1 vs $13.3 \%$ in normal control women but a follow up study from same group of a large cohort of donor oocytes $>2600$ did not show any significant differences in implantation, pregnancy and miscarriage rates between BMI groups. Although a composite measure of ongoing pregnancy/cycle was calculated and shown to be significantly lower in the obese cohort. ${ }^{62}$ Metwaily et al..$^{63}$ conducted a metaanalysis in 2008 \&showed the risk of miscarriage at $<20 \mathrm{wks}$ gestation was higher in both spontaneous as well as ART conceptions with an odds ratio of 1.67. In the study group analysis it was confirmed in donor oocyte cycles but not in general cohort undergoing ICSI. ${ }^{63}$ Lasheri also showed a higher risk of recurrent abortions in a big obese cohort with an odds ratio of 3.5. ${ }^{64}$ Also obesity is a known risk factor for recurrent pregnancy loss (RPL). ${ }^{65}$ In a study where chromosome analysis of 115 miscarriage specimens was done on women having RPL it was shown that obese group had euploid miscarriages which suggests obesity has an independent effect on endometrium. ${ }^{66}$

Also leptin is known to affect endometrium. Leptin receptors are known to be expressed in the endometrial endothelial cells in culture. ${ }^{67}$ Leptin causes a remodeling of human endometrial epithelium which stimulates proliferation and apoptotic cell pathways in vitro. ${ }^{68}$ There is upregulation of markers of receptivity with leptin exposure both in epithelial and stromal cells. ${ }^{67}$ 


\section{Transgenerational effect}

Increasing evidence suggests that metabolic obesity confers a risk of metabolic dysfunction through multiple generations. Obesity affects intergenerational risk, meaning risk to offspring of developing disease later in life. Children of obese mothers have more chance of developing obesity, type II diabetes and cardiovascular diseases as adults. ${ }^{69}$ This maybe due to epigenetic modifications in utero. In the DIO mouse models, pups are smaller at birth but they should catch up over growth and development of metabolic syndrome. ${ }^{70}$ Gene expression in the placentas of dams with DIO shows alterations in imprinted genes and genes regulating lipid metabolism. ${ }^{71}$ Nomura et $\mathrm{al}^{72}$ examined the placentas of obese mothers and found increased levels of global methylation. ${ }^{72} \mathrm{~A}$ recent study in a DIO mouse model showed that the metabolic dysfunction mediated through impaired mitochondrial dynamics can be passed through the maternal germline to $2^{\text {nd }}$ and $3^{\text {rd }}$ generation offspring. ${ }^{73}$ The authors showed that maternal diet induced MS in an inbred mouse models results in transgeneration inheritance of aberrant mitochondrion. An expression of mitochondrial chain complex and dynamic proteins was seen in $1^{\text {st }}$ through $3^{\text {rd }}$ generation offspring (F1-F3) despite the fact that they were eating a regular diet immediately after weaning. The transmission appeared to be germline and through aberrant oocytes. In humans with diets of children closely paralleling those of their parents, the effect of maternal metabolic syndrome may be>than in the mouse model.

\section{Management of obesity}

\section{Weight loss effects}

In 170 women having IVF short term weight loss was associated with a greater yield of metaphase II oocytes in obese women but clinical pregnancy rates and LBR's were not affected. ${ }^{20}$ Kort et al. ${ }^{74}$ studied 52 overweight/obese women with infertility who were referred for weight loss counseling with a goal of $10 \%$ weight loss. $32 \%$ patients achieved this goal and these patients had significantly high pregnancy rates and LBR's. ${ }^{74}$ Similarly in a RCT of 49 obese women having fertility treatment those who received intensive $12 \mathrm{wk}$ life style intervention had $6.6 \mathrm{~kg}$ weight loss and significantly greater live birth rates as compared to control $44 \%$ vs $14 \%$ and needed lower treatment cycles [2 vs 4$].^{75}$

A large RCT was carried out by Mutsaerts in 600 obese infertile women who received $18 \mathrm{mths}$ life style intervention before infertility treatment vs prompt treatment for $24 \mathrm{mths}$.Marked discontinuation rates was found in intervention group (21.8\%). Only $43 \%$ reached a target discontinuation of $5 \%$ weight loss. Significantly higher primary outcomes of a live vaginal delivery was seen in immediate treatment group [35.2\%VS 27.1\%) There was no difference in LBR when carried upto $24 \mathrm{mths}$ of treatment for both grps. ${ }^{76}$ Still it remain unanswered whether delaying infertility treatment helps or not but one advantage of obtaining weight loss is pregnancy risks get decreased by weight loss like PIH etc. ${ }^{77}$

\section{Lifesyle Intervention/exercise and newer antiobesity therapies}

\section{Role of exercise}

A lot of work has been done to see the effect of physical activity in obese infertile patients independently from weight loss. In a retrospective group of obese infertile women who underwent IVF/ ICSI, outcomes of patients who engaged in regular physical activity were compared with those who were sedentary as assessed by the validated Global Physical Activity Questionaire. Significantly higher pregnancy rates and LBR's were found in the active group(41cycles with a 3.71 relative risk of live birth. ${ }^{78}$ Wise et al. ${ }^{79}$ explored the effect of exercise on time to pregnancy in a big Danish group comprising of 3628 patients .They followed an inverse relationship between fecundity and vigorous physical activity when comparing women who completed $>5 \mathrm{hrs} /$ week to those who did not. However the relationship did not exist for overweight or obese women who performed vigorous physical activity. Moderate physical activity was associated with small rise in fecundity across the cohort. ${ }^{79}$ Physical activity has been associated with reduced systemic inflammatory mediators which may contribute to the improvement in fertility suggested by the sum of evidence. ${ }^{80}$

\section{Dietary factors}

There is no effect on fertility just by increased caloric intake but by distribution of those calories across food groups. In a study comparing dietary factors in women with PCOS in USA and Italy it was noted that the American women had>average body mass and higher CVS risk (impaired GTT, caloric intake was similar for both cohorts, but American ladies ingested more saturated fats. ${ }^{81} \mathrm{~A}$ follow up study sought to find the prevalence of MS in Italian PCOS group which approaches $50 \%$ in American women with PCOS. It was much lesser in Italian women(8-16\%) depending on the diagnostic criteria used. ${ }^{82}$ These studies and others on prevalence including obesityand type II diabetes across populations led to interest in the main therapeutic benefit of Mediterranean diet" characterized by >intake of unsaturated fats, and lower intake of animal fats and lower intake of omega6to omega 3 fatty acids. ${ }^{83}$ Sticking to Mediterranean diet" for $2 y$ rs in patients with metabolic syndrome significantly decreased IR and serum concentration of inflammatory markers including CRP and IL- $6 .{ }^{84}$ Dietary patterns of 161 couples who underwent IVF/ICSI was compared by Vujkovic et al. ${ }^{84}$ and compared 2 categories a health conscious low processed diet vs a Mediterranean diet compared to an increased chance of pregnancy. ${ }^{84}$ Spanish nested case control study compared the dietary patterns of fertile and infertile women categorized as western or primary Mediterranean diet". A lower risk of infertility was seen in women in the highest quartile of adherence to the Mediterranean diet. ${ }^{85}$ Work has been done by Chavarrone et al. ${ }^{86}$ on fertility diet, a pattern of diet intake which has been associated with lower risk of ovulatory infertility and characterized by<consumption of low glycaemic carbohydrates, high fat dairy and multivitamin. ${ }^{86-89}$ They followed a cohort of 17,000 women in the Nurses Health Study for $8 \mathrm{y}$ ears when they attempted pregnancy. They were given dietary scores based on their adherence to the fertility diet. Women in the highest quartile of adherence has an adjusted relative risk of 0.34 for ovulatory infertility, suggesting a significant impact of diet. ${ }^{90}$ Since understanding of mechanisms of underlying obesity's impact on fertility has provoked investigation of targeted dietary supplementation. Given that ROS have been implicated in oocyte mitochondrial dysfunction, antioxidants may moderate obesity's impact on the ovary. An important antioxidant in the electron transport chain is coenzyme Q10, which has been shown to decrease with aging. ${ }^{91}$ In an aged murine model, mice supplemented with CoQ-10 had higher rates of ovulatory and larger litter size. This correlated with lower mitochondrion DNA copy number indicating $<$ mitochondrial 
stress. ${ }^{91}$ A small randomized trial in older women undergoing IVF showed potential benefit with lower rates of aneuploidy and higher pregnancy rates. ${ }^{92}$ Results of Q10 supplementation in the DIO mouse model have had varying results. CoQ 10 did not decrease the levels of ROS in obese mice, but it did appear to improve oocyte mitochondrial distribution and spindle and chromosome alignment. ${ }^{93}$ CoQ10 has been studied in PCOS population-in a RCT of 100 patients undergoing ovulation induction had previously been resistant to clomiphene showed that $\mathrm{CoQ} 10$ supplementation improved ovulation and pregnancy rates. ${ }^{94}$ These studies have still got to be tried in the obese infertile populations.

\section{Bariatric surgery}

There is limited literature available on the effect of bariatric surgery on reproductive health outcomes. Pregnancy outcomes following bariatric surgery was examined in a retrospective study which showed there was lower risk of gestational DM and large for gestational age infants but it also showed a concerning increase in risk of small for gestational age infants towards higher risk of still births and neonatal deaths with no improvement in preterm births. ${ }^{95}$ In a survey study of 195 female patients in bariatric surgery $71 \%$ of women who were anovulatory before surgery had regained normal menses and this correlated with a higher degree of weight loss. ${ }^{96}$ In a prospective group of 29 morbidly obese women who underwent Roux-en Y bypass- $90 \%$ were ovulatory before surgery, which came as a surprise. The only significant change seen after surgery was a shortening of the follicular phase but the impact of this is unclear in the absence of fertility outcomes. ${ }^{97}$ Bariatric Surgery does appear to improve the PCOS phenotype. In a small study of 17 women who underwent biliopancreatic diversion or laparoscopic bypass, 16 did not sustain the diagnosis because of lowering of androgen levels by return of regular periods. Metabolic parameters including insulin sensitivity and BP were also improved. ${ }^{98}$ Again this showed that obesity had a marked impact on the pathophysiology of PCOS .Still many studies are required to see the effects of bariatric surgery on obesity related infertility.

\section{Role of weight loss medications}

Reviewed in ref 15 and further Legro $\mathrm{R}$ reviewed how few prospective studies have examined preconceptual weight loss interventions. ${ }^{99}$ Although some effective medications like liraglutide (GLP1R agonist), Qsymia (topiramate/phentermine), contrive (naltrexone/bupropion) are available in USA, we do not have either liraglutide/Qsymia available. We have reported our experience of topiramate alone in ovulation induction [100]in morbidly obese women and since tolerance develops to the effects of topiramate and although no teratogenic effects have been reported in those women receiving topiramate as an anticonvulsant except for occasional cleft lip there is need to develop more effective weight loss therapies which cause significant weight loss and most importantly report the effects in preconceptional intervention on important perinatal outcomes like live birth and the health of the infant and mother. The current data from RCT which come closest to meeting these criteria have not documented improved LBR after the interventions compared with control groups. There is a tendency for equating results from most successful treatments of morbid obesity like bariatric surgery with an average $40 \%$ weight loss suggest a mixed risk benefit ratio on perinatal outcomes. Though interventions to control gestational weight gain have been more completely studied than preconception ones and have documented successful interventions to achieve appropriate weight gain there is no clear evidence regarding controlling gestational weight gain actually improves any important perinatal outcomes. Future studies are needed for more successful and effective interventions, capture perinatal outcomes instead of weight changes as the primary outcome use at least at preconception, develop newer antiobesity drugs and study bariatric surgery in prospective trials to improve understanding of effectiveness of obesity treatment before pregnancy. ${ }^{99}$

\section{Conclusion}

There is an indication that obesity impacts on risks of sub fertility. It is not only by causing decreased fecundity but also it causes suboptimal responses to ART. Laboratory work has shown varied mechanisms which affect the oocyte, endometrium and pre implantation embryo by inducing weight loss, physical activity, dietary changes and bariatric surgery there is some promise for obese patients wanting to conceive. Yet still more work is needed to understand the interplay between obesity and reproduction, with the aim of building healthy families.

Onsaturated fats, lower intake of animal fats and lower intake of omega 6 to omega 3 fatty acids ${ }^{83}$ Sticking to Mediterranean diet for $2 \mathrm{yrs}$ in pts with MS.

\section{Acknowledgements}

None.

\section{Conflict of interest}

There is no conflict to publish the article in this Journal.

\section{References}

1. WHO. World Health Services. World Health Organization. Geneva, Switzerland; 2015.

2. Finucane MM, Stevens GA, Cowan MJ, et al. National, regional, and global trends in body mass index since 1980: systematic analysis of health examination surveys and epidemiological studies with 960 country-years and 9.1 million participants. Lancet. 2011;12:377(9765):557-607.

3. Vahratian A. Prevalence of overweight and obesity among women of child bearingage: results from the 2009 National Survey of Family growth. Matern Child Health J. 2009;13(2):268-273.

4. Kochar Kaur K, Allahabadia GN, Singh M. An update on Aetiopathogenesis and management of Obesity. Obes Control Ther 2016;3(1):1-17.

5. Kochar Kaur K, Allahabadia GN, Singh M. Current management of obesity in an infertile female. Recent advances and future prospectives. Drugs J Pharm Nutr Soc. 2013;3:1-13.

6. Kochar Kaur K, Allahabadia GN, Singh M. Further update on the Management of obesity with emphasis on genetic perspective. BAOJ Obe Weigh Manage. 2016;3(1):1-17.

7. Kochar Kaur K, Allahabadia GN, Singh M. A Review on Nutrient Metabolism with special emphasis on fatty acid metabolism. BAOJ Food Sci \&Tec. 2017;1:001.

8. Rachon D, Teede H. Ovarian function and obesity-relationship impact on womens reproductive lifespan and treatment options. Mol Cell Endocrinol. 2010;316(2):172-179.

9. Junghem ES, Moley KH. Current knowledge of of obesity's effect in the pre and periconceptual periods and avenues for future research. Am J Obstet Gynecol. 2010;203(6):525-530. 
10. Pasquali R. Obesity and androgens: facts and perspectives. Feril Steril. 2006;85(5):1319-1340.

11. Moran LJ, Norman RJ, Teede HJ. Metabolis risks in PCOS phenotype and adiposity impact. Trends Endocrinol n Metab. 2015;26(3):136-143.

12. Escobar-Morreale H. Surgical management of metabolic dysfunction in PCOS. Steroids. 2012;27(4):312-316.

13. Alvarez Biasco F, Botella Carretero JL, San MilanJL, et al. Prevalence and characteristics of the polycystic ovary syndromein overweight and obese women. Arch Intern Med. 2006;166(19):2081-2086.

14. Yildiz BO, Knochenhauer ES, Azziz R. Impact of obesityon the risk for poly cystic ovary syndrome. $J$ Clin Endocrinol Metab. 2008;93(1):162-168

15. Kochar Kaur K, Allahabadia GN. Medical management of an obese PCOS female. Proceedings of Wprld Congress on Ovulation Induction, September Seychelles; 2015.

16. Wise LA, Rothman KJ, Mikkelsen EM, et al. An internet based prospective study of body size and time to pregnancy. Hum Reprod. 2010;25(1):253-264.

17. Ramlau-Hansen CH, Thulstrup AM, Nohr EA, et al. Subfecundity in overweight and obese couples. Hum Reprod. 2007;22(6):1634-1637.

18. Gesink Law DC, Maclehose RF, Longnecker MP. Obesity and time to pregnancy. Hum Reprod. 2007;22(2):414-420.

19. Van der Steeg JW, Steures P, Eijkermans ML, et al. Obesity affects spontaneous pregnancy chances in subfertile. Ovulatory women. Hum Reprod. 2008;23(2):324-328.

20. Marquard KL, Stephens SM, Jungheim ES, et al. Polycystic ovary syndrome and maternal obesiy affect oocyte size in in vitro fertilization/intra cytoplasmic sperm injection cycles. Fertil Steril. 2011;95(5):2146-2149.

21. Shah DK, Mosmer SA, Berry KF, et al. Effect of obesity and embryo quality in women undergoing in vitro fertilization. Obstet Gynecol. 2011;118(1):63-70.

22. Luke B, Brown MB, Stern JE, et al. Female obesity adversely affects assisted reproductive technology (ART) pregnancy and live birth rates. Hum Reprod. 2011;26(1):245-252.

23. Jungheim ES, Lanzendorf SE, Odem RR, et al. Morbid obesity is associated with lower clinical pregnancy rates after in vitro fertilization in women with polycystic syndrome. Fertil Steril. 2009;92(1):756-761.

24. Chavarro JE, Ehrlich S, Colari DS, et al. Body mass index and short term weight change in relation to treatment outcomes in women undergoing assidted reproduction. Fertil Steril. 2012;98(1):109-116.

25. Koning AM, Mutsaerts MA, Kuchenbecker WK, et al. Complications and outcomes of assisted reproduction technologies in overweight and obese women. Hum Reprod. 2012;27:457-467.

26. Tortoriello DV, Mc Minn J, Chua SC. Dietary induced obesity and hypothalamic infertility in female DBA/21 mice. Endocrinology. 2004; $145: 1238-1247$.

27. Tortoriello DV, Mc Minn J, Chua SC. Increased expression of hypoyhalamic leptin receptor and adiponectin accompany resistance to dietary induced obesity and infertility in female C57BL/6J mice. Int $\mathrm{J}$ Obes(Lond). 2007;31(3):395-402.

28. Brannan JD, Schmidt SM, Kreger DO, et al. Baseline nonfasting serum leptin concentration to body mass index ratio is predictor of IVF outcomes. Hum Reprod. 2001;16(9):1819-1826.

29. Jain A, Polotsky AJ, Rochester D, et al. Pulsatile luteinizing hormone amplitude and progesterone metabolite excretion are reduced in obese women. J Clin Endocrinol Metab. 2007;92(7):2468-2473.
30. Robker RL, Akison LK, Bennet BD, et al. Obese women exhibit differences in ovarian metabolites, hormones and gene expression compared with moderate weight women. J Clin Endocrinol Metab. 2009;94(5):1533-1540.

31. Souter I, Baltagi LM, Kuleta D, et al. Women, weight and fertility: the effect of body mass index on the outcome of super ovulation/intra uterine insemination cycles. Fertil Steril. 2011;95(3):1042-1047.

32. Fedorcsak P, Dale PO, Storeng R, et al. Impact of overweight and underweight on assisted reproduction treatment. Hum Reprod. 2004;19(11):2523-2528.

33. Pinborg A, Gaarslev C, Hougaard CO, et al. Influence of female bodyweight on IVF outcomes in longitudinal multicentre cohort study of 487 infertile couples. Reprod Biomed Online. 2011;23(4):490-499.

34. Jungheim ES, Schoeller EL, Marquard KL, et al. Diet induced obesitymodel: abnormal oocytes and persistent growth abnormalities in the offspring. Endocrinology. 2010;151(8):4039-4046.

35. Luzzo KM, Wang O, Purcell SH, et al. High fat diet induced development defects in the mouse oocytes meiotic aneuploidy and fetal growth retardation/brain defects. PLoS One. 2012;7(11):e49217.

36. Machtinger R, Combelles MH, Missmer SA, et al. The association between severe obesity and characteristics of failed fertilized oocytes. Hum Reprod. 2012:27(11):3198-3207.

37. Igosheva N, Abramov AY, Poltson L, et al. Maternal diet induced obesity alters mitochondrial activity and redox status in mouse oocytes and zygotes. PLoS One. 2010;5(4):e10074.

38. Grindler NM, Moley KH. Maternal obesity, infertility and mitochondrial dysfunction :potential mechanisms emerging from mouse model systems. Mol Hum Reprod. 2013;19(8):486-494.

39. Wu LL, Dunning KR, Yang X, et al. High fat diet causes lipotoxicity responses in cumulus oocyte complexes and dereased fertilization rates. Endocrinology. 2010;151(11):5438-5445.

40. Palomba S, Daollo J, La Salla GB. Oocyte competence and decreased fertilization rates. Trends Endocrinol Metab; 2016.

41. Sorensen TI, Virtue S, Vidal-Pug A. Obesity as a clinical and public health problems: Is there a need for a new definition based on lipotoxicity effects? Biochim Biophys Acta. 2010;1801(3):400-404.

42. Broughton DE, Jungheim ES. A focused look on obesity and the preimplantation trophoblast. Semin Reprod Med. 2016;34(1):5-10.

43. Jungheim ES, Macones GA, Odem RR, et al. Association between free fatty acids, cumulus oocyte complex morphology and ovarian function during in vitro fertilization. Fertil Steril. 2011;95:1970-1974.

44. Virtue S,Vidal Puig A. Adipose tissue expandability, lipotoxicity and the metabolic syndrome-an allostatic perspective. Biochim Biophys Acta. 2010;1801(3):338-349.

45. Norwitz ER, Schust DJ, Fisher SJ. Implantation and survival of early pregnancy. N Engl J Med. 2001;345(19):1400-1408.

46. Hill MJ, Uyehara CF, Hashiro GM, et al. The utility of serum leptin and follicular fluid leptin, estradiol and progesterone levels during an in vitro fertilization cycle. J Assist Rdeprod Genet. 2007;24:183-188.

47. Lin O, Poon SL, Chen J, et al. Leptin interferes with 3'5'-cyclic adenosine monophosphate (Camp) signaling to inhibit steroidogenesis in human granulosa cells. Reprod Biol Endocrinol. 2009;7:115.

48. Brannan JD, Zhao Y, McElroy M. Leptin inhibits gonadotropin stimulated granulosa cell progesterone production by antagonizing insulin action. Hum Reprod. 1999;14:1445-1448.

49. Griesen S, Ledet T, Mollier N, et al. Effects of leptin on basal and FSH stimulated steroidogenesis in human granulosa-lutealcells. Acta Obstet 
Gynecol Scand. 2000;79(11):931-935.

50. Aggarwal SK, Vogel K, Weitsman SR, et al. Leptin antagonizes the insulin like growth factorl augmentation of steroidogenesisin granulose and theca cells of the human ovary. $J$ Cln endocrinol Metab. 1999;84(3):1072-1076.

51. Canell DT, Jones KP, Petersen CM, et al. Body mass index is inversely related to intra follicular HCG concentrations, embryo quality and IVF outcome. Reprod Biomed Online. 2001;3(2):109-111.

52. Metwailly M, Cutting R, Tipton A, et al. Effect of increased body mass index on oocyte and embryo quality in IVF patients. Reprod Biomed Online. 2007;15(5):532-538.

53. Leary C, Leese HJ, Sturmey RG. Human embryos from overweight and obese women display phenotypic and metabolic abnormalities. Hum Reprod. 2015;30(1):122-132.

54. Jungheim ES, Louden ED, Chi MM, et al. Preimplantation exposure of mouse embryos to palmitic acidresults in fetal growth restriction followed by catch up groleveidwth in the offspring. Biol Reprod. 2011 ; 85(4):678-683.

55. Jungheim ES, Macones GA, Odem RR, et al. Elevated serum alphalinoleic acids are associated with decreased chance of pregnancy after in vitro fertilization. Fertil Steril. 2011;96(4):880-883.

56. Jungheim ES, Fro V, lova AJ, et al. Relationship between polyunsaturated fatty acids and pregnancy in women undergoing in vitro fertilization. $J$ Clin Endocri nol Metab. 2013;98(8):E1364-E1368

57. Magarinos MP, Sanchez Margalet V, Kotler M, et al. Leptin promotes cell proliferation and survival of trophoblast cells. Biol Reprod. 2007;76(2);203-210.

58. Styne Gross A, Elkind-Hirsch K, Scott RT. Obesity does not impact implantation rates or pregnancy in women attempting conception through oocyte donation. Fertil Steril. 2005;83(6):1629-1634.

59. Wattanakumtorgul S, Damano MA, Stevens Hall SA, et al. Body mass index and uterine receptivity in the oocyte donation. Fertil Steril 2003;80(2):336-340

60. Dessole L, Darai E, Cornet D, et al. Determinants of pregnancy rates in the donor oocyte model: A multi variate analysis of 450 frozen thawed embryo transfers. Hum Reprod. 2009;24(12):3082-3089.

61. Rhee JS, Saberi JL, Mayer AL, et al. Diet induced obesity impair endometrial stromal cells decidualization: Apotential role for impaired autophagy. Hum Reprod. 2016;31(6):1315-1326.

62. Belver J, Melo MA, Bosch E, et al. Obesity and poor reproductive outcome: the potential role of endometium. Fertil Steril. 2007;88(2):446-451.

63. Metwally M, Ong KJ, Ledger WL. Does high body mass index increase the risk of miscarriage after spontaneous and assisted conception? Ametaanalys is of the evidence. Fertil Steril. 2008;90(3):714-726.

64. Lashen H, Fear K, Sturdee DW. Obesity is associated with increased risk of of first trimester and recurrent miscarriage: matched case control study. Hum Reprod. 2004;19(7):1644-1646.

65. Metwally M, Saravelos SH, Ledger WL, et al. Body mass index and risk of miscarriage in women with recurrent miscarriage. Fertil Steril. 2010;94(1):290-295

66. Boots CL, Bernhardt LA, Stephenson MD. Frequency if euploid miscarriage is increased in obese women with recurrent early pregnancy loss. Fertil Steril. 2014;102(2):455-459.

67. Gonzalez RR, Leavis P. Leptin upregulates beta 3integrin expression and interleukin lbeta ,upregulates leptin and leptin receptors in human endometrial epithelial cultures. Endocrine. 2001;16(1):21-28.

68. Tanaka T, Umesaki N. Leptin regulates the proliferation and apoptosis of human endometrial epithelial cells. Int J Mol Med. 2008;22(5):683-689.

69. Van Dijk SK, Molloy PL,Varinli H, et al. Epigenetics and human obesity. Int J Obes (Lond). 2015;39(1):85-97.

70. Jungheim ES, Schoeller EL, Marquard KL, et al. Diet induced obesity model: Abnormal oocytes and persistent growth abnormalities in the offspring. Endocrimology. 2010;151(8):4039-4046.

71. Sasson JE, Vinis AP, Mainigi MA, et al. Pre gestational vs gestational exposure to maternal obesity differentially programs the offspring in mice. Diabetologia. 2015;58:615-24.

72. Nomura Y, Lambertini I, Rialdi A, et al. (2014) Global methylation in the placenta and umbilical cord blood from pregnancies with maternal gestational diabetes, preeclamosia and obesity. Reprod Sci. 2014;21(1):131-137.

73. Saben JL, Boudores AL, Asghar Z, et al. Maternal metaboli syndrome programs mitochondrial dysfunction via germ line changes across three gestations. Cell Rep. 2016;16(1):1-8.

74. Kort JD, Winget C, Kim SH, et al. A retrospective cohort study to evaluate the impact of meaningful weightloss on fertility outcomes in an overweight population with infertility. Fertil Steril. 2014;101(5):1400-1403.

75. Sim KA, Dewizarnaulds GM, Denver GS, et al. Weight loss improves reproductive outcomes in obese women undergoing fertility treatment: a randomized controlled trial. Clin Obes. 2014;4(2):61-86.

76. Mutsaerts MA, Van Oers A M, Groen H, et al. Randomized trial of a lifestyle programme in obese infertile women. $N$ Engl $\mathrm{J} \mathrm{Med}$. 2016;374:1942-1953.

77. American College of Obstetricians \& Gynecologists. Practice Bulletin Number 156. Obesity in pregnancy. Obstet Gyneco. 1126:e112-e36.

78. Palomba S, Falbo A, Valli B, et al. Physical activity before IVF and ICSI cycles in infertile obese women: an observational cohort study. Reprod Biomed Online. 2014;29(1):72-79.

79. Wise LA, Rothman KJ, Mikkelsen EM, et al. A prospective cohor study of physical activity and time to pregnancy. Fertil Steril. 2012;97(5):1136-1142

80. Farinha JB, Steckling FM, Stefanello ST, et al. Response of oxidative stress and inflammatory biomarkers to a 12 week aerobic exercise training in women with metabolic syndrome. Sports Med Open. 2015;1(1):19.

81. Carmina E, Legro RS, Stamets K, et al. Difference in body weigh between American and Italian women with polycystic ovary syndrome. Hum Reprod. 2003;18(11):2289-2293.

82. Carmina E. Metabolic Syndrome in polycystic ovary syndrome. Minerva Gynecol. 2006;58(2):109-114.

83. Esposito K, Marfella R, Ciotola M, et al. Effect of a Mediterranean style diet on endothelial dysfunction and markers of vascular inflammation in the metabolic syndrome: a randomized trial. JAMA. 2004;292(12):1440-1446.

84. Vujkovic M, De Vries JH, Lindemans J, et al. The preconception Mediterranean dietary pattern in couples undergoing in vitro fertilization/ intracytoplasmic sperm injection treatment increases the chance of pregnancy. Fertil Steril. 2010;94(6):2096-2101

85. Toledo E, Lopez de Burgo C, Ruiz Zambrana A, et al. Dietary patterns and difficulty conceiving:a nested case-control study. Fertil Steril. 2011;96(5):1149-1153

86. Chavaro JE, Rich Edwards JW, Rosner BA, et al. Diatary fatty acid intakes and the risk of ovulatory infertility. Am J Clin Nutr. 2007;85(1):231-237.

87. Chavaro JE, Rich Edwards JW, Rosner BA, et al. Protein intake and ovulatory infertility. Am J Obstet Gynecol. 2018;198(2):210.e1-210.e7. 
88. Chavaro JE, Rich Edwards JW, Rosner BA, et al. Use of multivitamins, intake of B vitamins, and risk of ovulatory infertility. Fertil Steril. 2008;89(3):668-676

89. Chavaro JE, Rich Edwards JW, Rosner BA, et al. A prospective study on dairy foods intake and anovulatory infertility. Hum Reprod. 2007;22(5):1340-1347.

90. Chavaro JE, Rich Edwards JW, Rosner BA, et al. Diet and lifestyle in the prevention of ovulatory disorder infertility. Obstet Gynecol. 2007;110(5):1050-1058.

91. Bentov Y, Casper RF. The aging oocyte-can mitochondrial function be improved. Fertil Steril. 2013;9(1):18-22.

92. Bentov Y, Hannam M, Jurisicova A, et al. Coenzym e Q10 supplementation and oocyte aneuploidy in women undergoing IVF/ICSI treatment. Clin Med Insights Reprod Health. 2014;8:31-36.

93. Boots CE, Boudores A, Zhang W, et al. Obesity induced oocyte mitochondrial defects are partially prevented and rescued by supplemention with Coenzym e Q10 in a mouse model. Hum Reprod. 2016;31(9):2090-2099.

94. El-Rafaeey A, Saleem A, Badawy A. Combined coenzyme Q10 and clomiphene citrate for ovulation induction in clomiphene citrate resistant polycystic ovary syndrome. Reprod Biomed Online. 2014;29(1):119-124.
95. Johansson K, Cnattinguis S, Naslund I, et al. Outcomes of pregnancy after bariatric surgery. $N$ Engl J Med. 2015;372(23):2267.

96. Teitelman M, Grotegut CA, Williams NN, et al. The impact of bariatric surgery on menstrual patterns. Obes Surg. 2006;16(11):1457-1463.

97. Legro RS, Dodson WS, GnatukCL, et al. Effects of gastric bypass surgery on female reproductive function. J Clin Endocrinol Metab. 2012;97(12):4540-4548.

98. Escobar Morreale HF, Botella Caretero JL, Alvarez Blasco F, et al. The polycysic ovay syncdome associated with morbid obesity may resolve after weight loss induced by bariatric surgery. J Clin Endocrinol Metab. 2005;90(12):6364-6368.

99. Legro RS. Effects of obesity treatment on female reproduction: results do not match expectations. Fertil Steril. 2017;107(4):860-867.

100. KocharKaur K, Allahbadia GN, Singh M. Topiramate-a novel drug in aiding ovulation induction (OI) in extremely obese PCOS patients resistant to any kind of OI- presented in the fifth world congress on ovulation induction held in Rome-Italy (13TH -15TH sept); 2007. 